\title{
Spark plasma sintering of zirconia/nano-nickel composites
}

\author{
Carlos F. Gutierrez-Gonzalez ${ }^{1,2, a}$, Nestor W. Solis Pinargote ${ }^{3}$, Said Agouram ${ }^{2}$, \\ Pavel Y. Peretyagin ${ }^{3}$, Sonia Lopez-Esteban ${ }^{4}$ and Ramon Torrecillas ${ }^{1,3}$ \\ 1 Centro de Investigación en Nanomateriales y Nanotecnología (CINN) [Consejo Superior de Investigaciones Científicas \\ (CSIC)-Universidad de Oviedo (UO)-Principado de Asturias (PA)]; Avenida de la Vega 4-6, 33940 El Entrego, Asturias, Spain \\ 2 Department of Applied Physics and Electromagnetism, Universitat de Valencia, 46100 Burjassot, Spain \\ 3 Moscow State University of Technology "STANKIN", 1 Vadkovsky per., 127994 Moscow GSP-4, Russian Federation \\ 4 Instituto de Ciencia de Materiales de Madrid (ICMM), Consejo Superior de Investigaciones Cientificas (CSIC), Cantoblanco, \\ 28049 Madrid, Spain
}

Received 24 September 2015, Accepted 15 October 2015

\begin{abstract}
This work describes a whole processing route for obtaining dense and nanostructured zirconianickel composites with low contents of metallic phase (1-3.5 vol\%). For the processing route, a combination of spray-freezing and lyophilization has been proposed. After the calcination and reduction of the resulting powders an X-ray and HRTEM characterization has been performed. This showed the formation of pure zirconia and nickel, well dispersed and homogeneously distributed, nanostructured phases. The obtained powders were subsequently sintered by Spark Plasma Sintering (SPS). As a result, dense $\mathrm{ZrO}_{2}-\mathrm{Ni}$ composites were obtained, revealing that the sizes of the metal particles were kept in the nanometer range and appear homogeneously and well dispersed into the ceramic matrix. The mechanical behavior of these materials was evaluated by means of the Vickers hardness, showing and increment of about $25 \%$ with respect to pure zirconia with only a Ni concentration of 1 vol\%.
\end{abstract}

Key words: Spark plasma sintering / nanomaterials / nanocomposites / nanoceramics / powder materials / zirconia-nickel composites / mechanical properties

\section{Introduction}

It is well known that the properties of metallic nanoparticles reinforced ceramic matrices strongly depend on their size, as well as distribution and morphology [1]. It has been demonstrated that the introduction of a nanometric component in different matrices improves drastically different properties, as mechanical, electromagnetical, etc. [1-4]. However, dealing with nanosized powders involves the use of techniques for controlling the growth of these tiny structures and the strong tendency of the nanoparticles to agglomerate [5].

Although many techniques have been used in order to obtain such materials, it has been found that the most successful are those that follow a wet synthesis route $[6,7]$. In this context spray and freeze-drying appear as suitable techniques for this purpose. Spraying is a technique that allows dividing the initial ceramic-metal suspension into very small drops increasing the freezing speed when sprayed over liquid nitrogen, avoiding seg-

${ }^{a}$ Corresponding author: cf.gutierrez@cinn.es regation between components. Once the suspension is frozen, lyophilization appears as a proper technique in order to remove water without passing throughout the liquid phase that would promote the separation of the components. A properly controlled lyophilization process sublimates water eliminating the capillary forces that cause nanoparticles agglomeration [8]. Therefore, lyophilization allows obtaining uniform powders by preventing the formation of dry agglomerates [9]. When using wet processing routes with liquid water there is a concentration phenomenon of the particles at the evaporation surface promoting them to coalesce.

Depending on the sinterization method for obtaining dense ceramic-metal nanocomposites, different microstructures and properties may be achieved $[10,11]$. Traditional sinterization methods as conventional sintering or Hot Press lead to materials with agglomerated nanoparticles because of the larger periods of sinterization that let these particles to merge. A homogeneous dispersion of particles into the matrix is very important when it comes to the behavior of ceramic-metal composites (cermets), especially for functional applications. 
In this context Spark Plasma Sintering appears as a suitable method to reach this purpose. The higher heating rates achievable by this technique combined with the application of an uniaxial force reduce drastically the sinterization period and thus the original powder nanostructure can be preserved.

The yttria-doped zirconia/nickel system proposed in this work could be the perfect candidate to model the mechanical properties of ceramic/metal nanocomposites. On one hand, the thermal expansion coefficients mismatch between nickel and zirconia is very small (less than 5\%) and therefore residual thermal stresses are supposed to be minimal. On the other hand, the grain growth of zirconia during sintering is almost negligible which minimizes the metal coarsening in the final compact. Moreover, the elastic moduli are nearly identical (200 GPa) and the difference in the lattice parameter of both components is about $2 \%$. This small misfit allows a satisfactory epitaxial growth of nickel on zirconia.

The aim of this work was to explain the potential of the lyophilization technique combined with the spray-freezing to prepare composite ceramic-metal materials powders with homogeneous and well dispersed metal nanoparticles as second phase. Moreover, Spark Plasma Sintering is presented as suitable technique to preserve the initial nanostructure of the powders in dense materials. The mechanical behavior of these nanocermets will be studied in terms of hardness.

\section{Experimental}

\subsection{Materials and synthesis}

The following commercially available powders have been used as raw materials: (1) Tetragonal zirconia polycrystals (3Y-TZP, 3 mol\% $\mathrm{Y}_{2} \mathrm{O}_{3}$; TZ-3YE, Tosoh Corp.), with an average particle size of $d_{50}=0.26 \pm 0.05 \mu \mathrm{m} ;(2)$ nickel (II) nitrate hexahydrate (Merck, Germany, 99.0\% purity, $\left.\mathrm{Ni}\left(\mathrm{NO}_{3}\right)_{2} \cdot 6 \mathrm{H}_{2} \mathrm{O}\right)$.

Nickel salt was dissolved in distilled water and the ceramic powder was added in order to obtain different concentrations. The suspensions were prepared with a $70 \mathrm{wt} \%$ of solids and a $1 \mathrm{wt} \%$ of surfactant. For this purpose three different $\mathrm{Ni}$ concentrations were selected (1 vol\% Ni, 2.5 vol\% $\mathrm{Ni}$ and $3.5 \mathrm{vol} \% \mathrm{Ni}$ ).

In order to homogenize the slurries, they were milled with zirconia balls for $24 \mathrm{~h}$ and after that the suspensions were sprayed over liquid nitrogen with an airbrush gun (Iwata Custom Micron SB airbrush, Iwata Medea, Inc., Portland, OR, USA) through a $0.18 \mathrm{~mm}$ diameter nozzle. The resulting frozen suspensions were lyophilized until completely dried in a lyophilizer (Cryodos-50, IMATELSTAR, S.L., Barcelona, Spain). The temperature of the cold finger in the lyophilizer is set at $-50 \pm 2{ }^{\circ} \mathrm{C}$. The freeze dryer shelf temperature and the chamber pressure during the entire process were $20 \pm 2{ }^{\circ} \mathrm{C}$ and $0.06 \pm$ mbar respectively in order to stay in the water vapor region of the water phase diagram during the whole process.
The resulting powder was calcined at $600{ }^{\circ} \mathrm{C}$ for $2 \mathrm{~h}$ in air in order to obtain $\mathrm{ZrO}_{2} / \mathrm{NiO}$ powders and then reduced at $500{ }^{\circ} \mathrm{C}$ in a $90 \% \mathrm{Ar} / 10 \% \mathrm{H}_{2}$ atmosphere in order to obtain a zirconia powder with nickel nanoparticles adhered on its surface.

The resulting powders were spark plasma sintered (SPS, FCT Systeme GMBH, HDP 25, Germany) under the conditions $1350{ }^{\circ} \mathrm{C}, 25 \mathrm{kN}, 5 \mathrm{~min}$ in hydrogen. As result, disks of $20 \mathrm{~mm}$ diameter and $3 \mathrm{~mm}$ thickness were obtained.

\subsection{Characterization}

X-Ray diffraction analysis on the different stages of the process was performed using $\mathrm{Cu} \mathrm{K}_{\alpha}$ radiation (XRD Bruker AXS D8 ADVANCE, with a SolX energydispersive detector) in order to identify the different phases along the process.

Powder characterization was performed by transmission electron microscopy (TEM), high resolution TEM (HRTEM) and energy dispersive X-ray spectroscopy (EDX-mapping) by using a field emission gun (FEG) TECNAI G2 F20 microscope operated at $200 \mathrm{kV}$.

The density of the sintered compacts was measured according to the Archimedes method. The hardness was measured on 30 different points for each concentration using a Vickers diamond microindenter (Leco 100-A Microindentation Hardness Testing System, USA) on surfaces of cross sections polished down to 1 micron, with an applied load of $0.9 \mathrm{~kg}(8.8 \mathrm{~N})$ for $15 \mathrm{~s}$. The hardness was determined according to equation $H_{\mathrm{v}}=1.853 \mathrm{P} / \mathrm{d}^{2}$, where $P$ stands for the applied load (in N) and $d$ stands for the diagonal length of the indentation in $\mathrm{mm}$.

For comparison purposes, a pure zirconia sample was also prepared following the same processing route and sintering conditions.

Fracture surfaces were studied in a Field Emission Scanning Electron Microscope (FE-SEM, Quanta FEG 650, FEI) with Energy Dispersive X-ray Microanalysis (Ametek-EDX, with an Apollo X detector).

\section{Results and discussion}

Figure 1 shows the X-ray diffraction of the $3.5 \mathrm{vol} \% \mathrm{Ni}$ sample after the powder reduction (a) and after the sintering process (b). These results show that after the reductions process no evidence of any nickel phases is present in the powders except the reduced nickel. It can also be observed the presence of monoclinic zirconia as a consequence of its presence in the starting powder. This fact confirms that the reduction process has been successful and efficient. After the sintering process (Fig. 1b), the Xray diffractogram only shows the presence of tetragonal zirconia and nickel metal. This evidences that no chemical reaction has occurred between the phases and that the starting monoclinic zirconia has been stabilized on its tetragonal phase. 


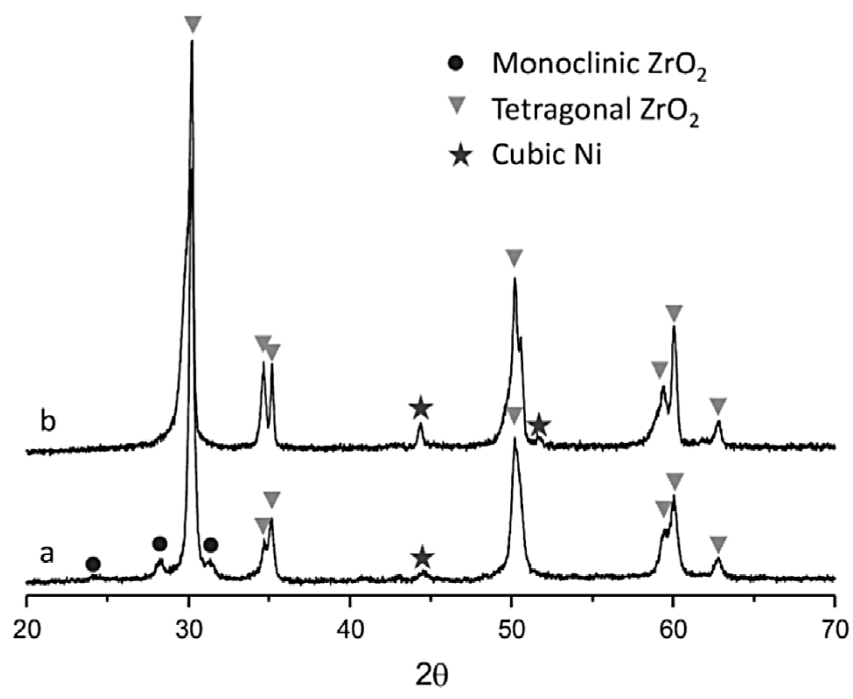

Fig. 1. X-ray diffractograms corresponding to: (a) the nanopowder with $3.5 \mathrm{vol} \% \mathrm{Ni}$ after the reduction process and (b) the sintered $3.5 \mathrm{vol} \% \mathrm{Ni}$ compact after sinterization.

TEM observations were carried out on the different powders after the reduction process. Figure $2 \mathrm{a}$ shows a representative image of the 2.5 vol\% Ni composite with an overlapped mapping image detecting the Ni location. This image shows that the obtained metal particles are in the nanometer range and appear homogeneously dispersed and attached to the zirconia surface nanoparticles. Figure 2b is a HRTEM image of a nickel nanoparticle attached on a zirconia nanoparticle in the $2.5 \mathrm{vol} \%$ $\mathrm{Ni}$ composite. This picture shows the clear lattice space of both components demonstrating that the nanoparticles are crystallized. In the case of the zirconia, an interplanar spacing of $2.55 \AA$ corresponds to the $\left(\begin{array}{lll}1 & 1 & 0\end{array}\right)$ planes. The nickel nanoparticle appears as a discrete, uniform and crystalline structure, with a size of approximately $20 \mathrm{~nm}$. This nanoparticle shows a well-defined lattice spacing of $2.05 \AA$, corresponding to the $\left(\begin{array}{lll}1 & 1 & 1\end{array}\right)$ planes of face-centered nickel cubic phase. It can also be observed that the interface between the nickel and zirconia nanoparticles is ordered and very arranged, showing an epitaxial growth of the metal nanoparticle over the ceramic phase. This fact can be due to two main reasons. On one hand, there are evidences that there is a very good lattice matching between $\mathrm{ZrO}_{2}$ and nickel, and on the other hand there is the influence of the mechanism of "evaporation-condensation" grain growth that is typical of the metallic nanoparticles [12-14]. It has been observed that this fact may lead to the improvement of the material characteristics as, for example, the mechanical properties of the sintered specimens.

The results for the density measurements after the sintering process are presented in Table 1 . For all cases, the density values are higher than the $99 \%$ of the theoretical value.

One of the reasons for selecting the spark plasma sintering as sinterization technique is because it offers the possibility to obtain dense materials keeping the initial
Table 1. Density of the different ceramic-metal Spark Plasma Sintered materials determined by the Archimedes method.

\begin{tabular}{ccc}
\hline Sample & Density (g.cm ${ }^{-3}$ ) & \% Density \\
\hline $1.0 \mathrm{vol} \% \mathrm{Ni}$ & $6.106 \pm 0.004$ & 99.7 \\
$2.5 \mathrm{vol} \% \mathrm{Ni}$ & $6.221 \pm 0.006$ & 99.9 \\
$3.5 \mathrm{vol} \% \mathrm{Ni}$ & $6.177 \pm 0.004$ & 99.9 \\
\hline
\end{tabular}

nanostructure present in the starting powders. Moreover, due to the very fast sintering slopes (in this case $\left.100{ }^{\circ} \mathrm{C} \cdot \mathrm{min}^{-1}\right)$ it is possible to achieve dense materials without using densification agents, and therefore improving handling and processing costs. Figure 3 is a representative SEM micrograph of a fracture surface of the 3.5 vol\% Ni composite. Around 150 nickel particles from each composition were measured using these pictures for measuring the $\mathrm{Ni}$ particle size in the sintered specimens. The mean size values of the Ni particle size in all the samples are plotted in Figure 4. As it can be observed, there is an increment on the $\mathrm{Ni}$ grain size when increasing the concentration. This has to be related with the fact that when increasing the $\mathrm{Ni}$ content, it is easier for the metallic particles to merge forming bigger aggregates.

Figure 5 shows the Vickers hardness for the different materials. Taking into account the Ni hardness (0.64 GPa) [15], the composite hardness is supposed to decrease when increasing the Ni content. However in this case, it can be observed that there is a noticeable increment of these values for the $\mathrm{Ni}$ concentrations studied in this work. In the case of $1 \mathrm{vol} \% \mathrm{Ni}$ this increment reaches a value of about $25 \%$ when compared to the pure zirconia. Therefore, a pronounced deviation from the expected linear correlation (the rule of mixing) is clearly observed. This behavior is fully predicted by the hardening model proposed by Pecharroman et al. [16] where the role of the nickel particle size and the good dispersion throughout the matrix, avoiding agglomeration, is determinant for obtaining the reached hardness values. For higher concentrations of $\mathrm{Ni}$ it can be observed that the hardness values start to decrease. This is because at higher concentrations of nickel, particles begin to coalesce increasing their size and thus reducing the Hall-Petch effect based on the strengthening of materials by decreasing their average crystallite size.

\section{Conclusions}

In this work it has been showed that spray freezing combined with lyophilization appears as a suitable technique to process nanostructured ceramic-metal powders. It has been shown, that the obtained powders present homogeneity and good dispersion of the metal phase. These metal nanoparticles have grown epitaxially on the ceramic grain surfaces, providing good interfaces, which is crucial for the sintering and to obtain improved mechanical properties in the sintered materials.

Spark plasma sintering appears as a feasible technique for obtaining dense and nanostructured zirconia-Ni 

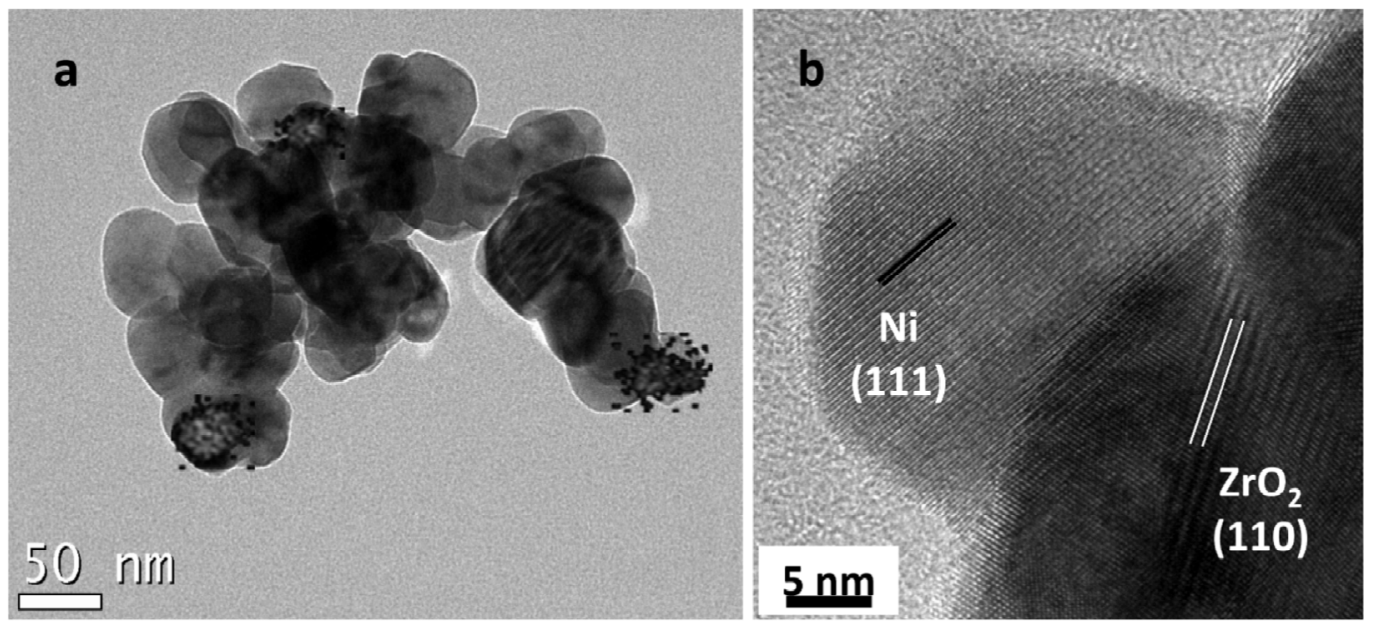

Fig. 2. (a) TEM micrograph of the 2.5 vol\% Ni powder with the overlap EDX mapping showing the location of the Ni nanoparticles. (b) HRTEM micrograph of a Ni nanoparticle epitaxially grown on the surface of a zirconia particle. The interface between both particles presents an excellent matching of atomic planes.

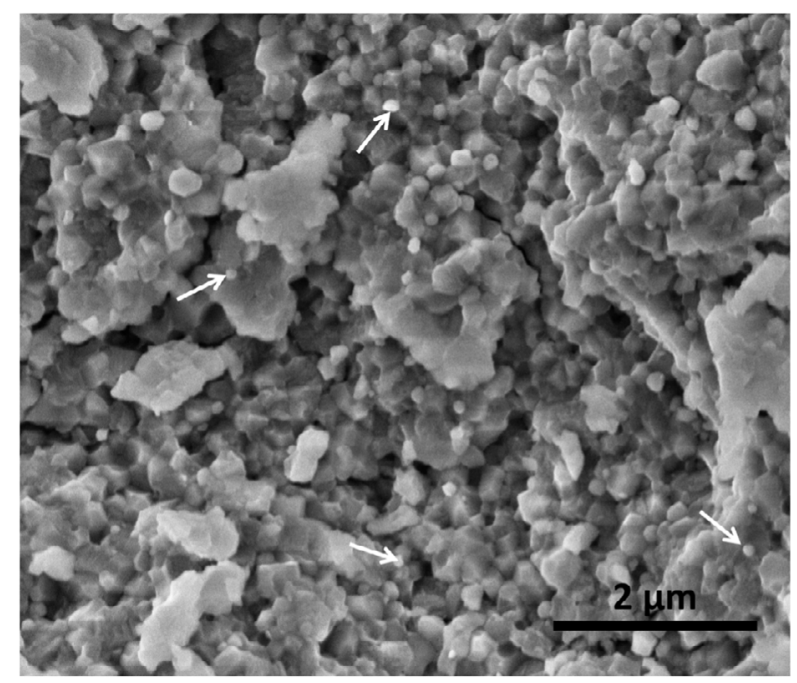

Fig. 3. FE-SEM image of the fracture surface of a 3.5 vol\% Ni. Arrows point at some randomly chosen $\mathrm{Ni}$ nanoparticles identified by EDX.

composites. The average grain size of the nickel particles in all composites has kept in the nanometer range and they appear homogeneously and well dispersed within the ceramic matrix. The higher heating rates, only achievable by the SPS technique, avoided the coalescence of the nickel particles providing an increment of about $25 \%$ of the zirconia Vickers hardness with only 1 vol\% of Ni.

Acknowledgements. Authors would like to thank The Ministry of the Russian Federation supported this work in the frame of Governmental Regulation of the Russian Federation No. 220, 9 April 2010 by contract 14.B25.31.0012, 26 June 2013.

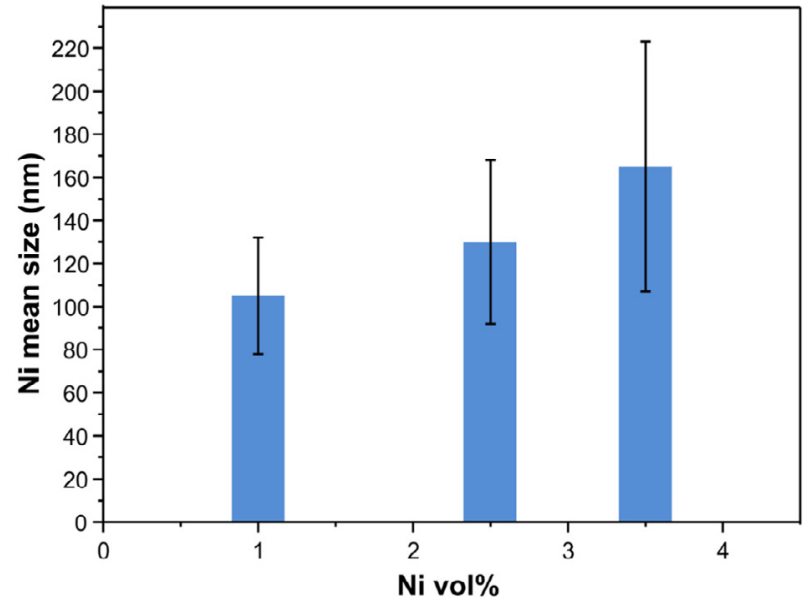

Fig. 4. Average size of Ni nanoparticles for the three different sintered composites.

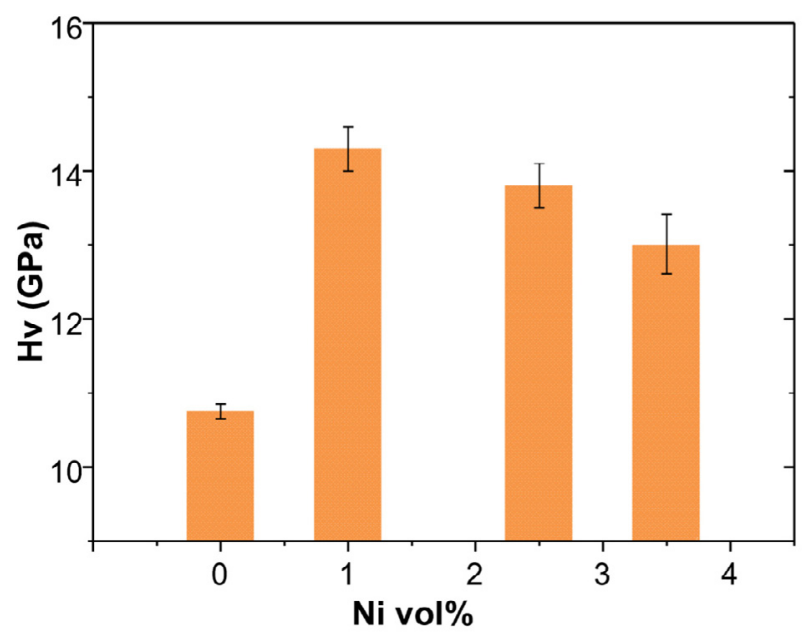

Fig. 5. Vickers hardness of the three $\mathrm{ZrO} 2-\mathrm{Ni}$ nanocomposites. The value corresponding to pure zirconia has been plotted for comparison purposes. 


\section{References}

[1] C. Burda, X. Chen, R. Narayanan, M.A. El-Sayed, Chemistry and properties of nanocrystals of different shapes, Chem. Rev. 105 (2005) 1025-1102

[2] J.S. Moya, S. Lopez-Esteban, C. Pecharroman, The challenge of ceramic/metal microcomposites and nanocomposites, Prog. Mater. Sci. 52 (2007) 1017-1090

[3] K.L. Kelly, E. Coronado, L.L. Zhao, G.C. Schatz, The optical properties of metal nanoparticles: The influence of size, shape, and dielectric environment, J. Phys. Chem. B 107 (2003) 668-677

[4] Y. Sun, Y. Xia, Shape-controlled synthesis of gold and silver nanoparticles, Science 298 (2002) 2176-2179

[5] J. Li, Y.U. Lin, B.G. Zhao, Spontaneous agglomeration of silver nanoparticles deposited on carbon film surface, J. Nanopart. Res. 4 (2002) 345-349

[6] L. Luo, J. Yao, J. Li, J. Yu, Preparation and characterization of sol-gel Al2O3/Ni-P composite coatings on carbon steel, Ceram. Int. 35 (2009) 2741-2745

[7] E.D. Rodeghiero, O.K. Tse, J. Chisaki, E.P. Giannelis, Synthesis And Properties Of Ni-Alpha-Al2O3 Composites Via Sol-Gel, Mat. Sci. Eng. A Struct. 195 (1995) 151-161

[8] B.E. Novich, C.A. Sundback, R.W. Adams, Quickset Injection Molding of High-Performance Ceramics, M.J. Cima. American Ceramic Society, Westerville, OH, 1992

[9] A.G. King, Ceramic Technology and Processing, William Andrew Publishing, New York, USA, Vol. 1, 2002, pp. $136-142$
[10] F. Esteban-Betegon, S. Lopez-Esteban, J. Requena, C. Pecharroman, J.S. Moya, J.C. Conesa, Obtaining Ni nanoparticles on 3Y-TZP powder from nickel salts, J. Am. Ceram. Soc. 89 (2006) 144-150

[11] C.F. Gutierrez-Gonzalez, J.F. Bartolome, Damage tolerance and $\mathrm{R}$-curve behavior of $\mathrm{Al} 2 \mathrm{O} 3-\mathrm{ZrO} 2-\mathrm{Nb}$ multiphase composites with synergistic toughening mechanism, J. Mater. Res. 23 (2008) 570-578

[12] J.S. Moya, T. Rodriguez-Suarez, S. Lopez-Esteban, C. Pecharroman, R. Torrecillas, L.A. Diaz, M. Nygren, Diamond-like hardening of alumina/Ni nanocomposites, Adv. Eng. Mater. 9 (2007) 898-901

[13] S. Lopez-Esteban, T. Rodriguez-Suarez, F. EstebanBetegon, C. Pecharroman, J.S. Moya, Mechanical properties and interfaces of zirconia/nickel in micro- and nanocomposites, J. Mater. Sci. 41 (2006) 5194-5199

[14] T. Rodriguez-Suarez, L.A. Diaz, S. Lopez-Esteban, C. Pecharroman, A. Esteban-Cubillo, L. Gremillard, R. Torrecillas, J.S. Moya, Epitaxial growth of tungsten nanoparticles on alumina and spinel surfaces, Nanotechnology 19(21) (2008) 215605

[15] G.V. Samsonov, Handbook of the Physicochemical Properties of the Elements, Springer US, Verlag US, 1968

[16] C. Pecharroman, F. Esteban-Betegon, J.F. Bartolome, G. Richter, J.S. Moya, Theoretical model of hardening in zirconia-nickel nanoparticle composites, Nano Lett. 4 (2004) $747-751$ 